\title{
An Elderly Japanese Patient with Adult-onset Type II Citrullinemia with a Novel D493G Mutation in the SLC25A13 Gene
}

\author{
Yoshimi Takahashi ${ }^{1}$, Shingo Koyama ${ }^{1}$, Hidetomo Tanaka ${ }^{1}$, Shigeki Arawaka ${ }^{1}$, \\ Manabu Wada ${ }^{1}$, Toru Kawanami ${ }^{1}$, Hiroaki Haga ${ }^{2}$, Hisayoshi Watanabe ${ }^{2}$, Kentaro Toyota ${ }^{3}$, \\ Chikahiko Numakura ${ }^{3}$, Kiyoshi Hayasaka ${ }^{3}$ and Takeo Kato ${ }^{1}$
}

\begin{abstract}
Mutations in the SLC25A13 gene lead to neonatal intrahepatic cholestasis caused by citrin deficiency and/ or adult-onset type II citrullinemia (CTLN2). A 62-year-old man presented with recurrent episodes of neuropsychiatric manifestations. On admission, he had disorientation and flapping tremor. Laboratory data showed hyperferritinemia in addition to postprandial hyperammonemia and citrullinemia. A liver biopsy specimen revealed moderate hemosiderin deposits and hepatocytes with macrovesicular fat droplets. Genetic analysis of the SLC25A13 gene identified the previously reported p.S225X mutation and a novel p.D493G mutation. Hyperferritinemia might also be a characteristic finding of CTLN2-related fatty changes of the liver.
\end{abstract}

Key words: adult-onset type II citrullinemia, citrin, hemosiderin, hyperferritinemia, novel mutation, $S L C 25 A$ 13

(Intern Med 51: 2131-2134, 2012)

(DOI: 10.2169/internalmedicine.51.7644)

\section{Introduction}

Mutations in the SLC25A13 gene can lead to neonatal intrahepatic cholestasis caused by citrin deficiency (NICCD) and/or adult-onset type II citrullinemia (CTLN2). Both of these conditions are inherited in an autosomal recessive fashion $(1,2)$. The clinical presentation of patients with CTLN2 is characterized by hyperammonemia accompanied by recurrent episodes of neuropsychiatric manifestations including aberrant behavior, nocturnal delirium, disorientation, consciousness disturbances, convulsive seizures, and coma (3). Most patients with CTLN2 have hepatic steatosis. Pancreatitis, hyperlipidemia, and hepatoma may also occur (4). We report a case of elderly-onset CTLN2 showing hyperferritinemia with hemosiderin deposits in the liver, as- sociated with a novel p.D493G mutation in the SLC25A13 gene.

\section{Case Report}

A 62-year-old Japanese man was admitted to our hospital because of recurrent episodes of consciousness disturbances and behavioral abnormalities during the previous 4 weeks. He had no history of prolonged neonatal jaundice, pancreatitis, or hypertension, but had mild liver dysfunction at a routine health check-up in the recent decade. He had a preference for eating beans and boiled eggs, but did not drink any alcohol. He previously consumed protein-rich meals for lunch almost every day. However, following his retirement from a construction company, he tended to eat carbohydraterich foods, such as noodles, for lunch, and had lost $5 \mathrm{~kg}$ of

\footnotetext{
${ }^{1}$ Department of Neurology, Hematology, Metabolism, Endocrinology, and Diabetology, Faculty of Medicine, Yamagata University, Japan, ${ }^{2}$ Department of Gastroenterology, Faculty of Medicine, Yamagata University, Japan and ${ }^{3}$ Department of Pediatrics, Faculty of Medicine, Yamagata University, Japan

Received for publication March 2, 2012; Accepted for publication April 19, 2012

Correspondence to Dr. Shingo Koyama, skoyama@med.id.yamagata-u.ac.jp
} 
Table. Laboratory Findings on Admission

\begin{tabular}{|c|c|c|c|}
\hline & Ref. range & & Ref. range \\
\hline White blood cell & $4410 / \mu \mathrm{L}(3800-9600)$ & $\mathrm{Fe}$ & $183 \mu \mathrm{g} / \mathrm{dL}(54-181)$ \\
\hline Red blood cell & $437 \times 10^{4} / \mu \mathrm{L}(431-565)$ & UIBC & $11 \mu \mathrm{g} / \mathrm{dL}(112-255)$ \\
\hline Hemoglobin & $14.0 \mathrm{~g} / \mathrm{dL} \quad(13.7-17.4)$ & Ferritine & $1124.0 \mathrm{ng} / \mathrm{mL}(30.0-400.0)$ \\
\hline Platelet & $12.0 \times 10^{4} / \mu \mathrm{L}(13.1-36.5)$ & Glucose & $112 \mathrm{mg} / \mathrm{dL}(70-109)$ \\
\hline Prothrombin time & $82.0 \%(82.0-124.0)$ & Ammonia & $30 \mu \mathrm{g} / \mathrm{dL}(0-100)$ \\
\hline Total protein & $6.4 \mathrm{~g} / \mathrm{dL}(6.7-8.3)$ & Lactate & $2.1 \mathrm{mmol} / \mathrm{L}(0.9-1.7)$ \\
\hline Albumin & $3.4 \mathrm{~g} / \mathrm{dL}(4.0-5.0)$ & PSTI & $243.1 \mathrm{ng} / \mathrm{mL}(\leq 20.0)$ \\
\hline Total bilirubin & $1.2 \mathrm{mg} / \mathrm{dL}(0.2-1.3)$ & Hyaluronic acid & $279 \mathrm{ng} / \mathrm{mL}(\leq 50.0)$ \\
\hline AST & $50 \mathrm{IU} / \mathrm{L}(13-33)$ & Type IV collagen & $154 \mathrm{ng} / \mathrm{mL}(\leq 150)$ \\
\hline ALT & $55 \mathrm{IU} / \mathrm{L}(8-42)$ & ICG (15 min) & $8 \%(0-10)$ \\
\hline ALP & 367 IU/L (115-359) & IgG & $1430 \mathrm{mg} / \mathrm{dL}(870-1700)$ \\
\hline $\mathrm{LDH}$ & 203 IU/L (119-229) & Plasma amino acid & \\
\hline$\gamma$-GTP & 96 IU/L (10-47) & Aspartate & $4.7 \mathrm{nmol} / \mathrm{mL}(<3.2)$ \\
\hline Cholinesterase & $156 \mathrm{IU} / \mathrm{L}(168-470)$ & Ornithine & $103.6 \mathrm{nmol} / \mathrm{mL}(43.2-95.7)$ \\
\hline Amylase & $122 \mathrm{IU} / \mathrm{L}(37-125)$ & Citrulline & $131.4 \mathrm{nmol} / \mathrm{mL}(20.4-44.8)$ \\
\hline Triglyceride & $300 \mathrm{mg} / \mathrm{dL}(30-149)$ & Arginine & $81.7 \mathrm{nmol} / \mathrm{mL}(46.0-121.7)$ \\
\hline HDL cholesterol & $25 \mathrm{mg} / \mathrm{dL}(41-96)$ & Urine amino acid & \\
\hline Total cholesterol & $139 \mathrm{mg} / \mathrm{dL}(128-219)$ & Citrulline & $31.9 \mu \mathrm{mol} / \mathrm{L}(<21.7)$ \\
\hline BUN & $20 \mathrm{mg} / \mathrm{dL}(8-22)$ & & \\
\hline Creatinine & $0.89 \mathrm{mg} / \mathrm{dL}(0.61-1.04)$ & & \\
\hline
\end{tabular}

AST: aspartate aminotransferase, ALT: alanine aminotransferase, PSTI: pancreatic secretory trypsin inhibitor, ALP: alkaline phosphatase, LDH: lactate dehydrogenase, $\gamma$-GTP: gamma glutamyl transpeptidase, HDL: high-density lipoprotein, HbA1c: Hemoglobin A1c in Japan Diabetes Society value, ICG (15 min): indocyanine green retention rate in $15 \mathrm{~min}$

body weight during the preceding 3 months.

On admission, the patient was disoriented with regard to time, place, and his age. His blood pressure was 122/81 $\mathrm{mmHg}$. The patient was lean with a body mass index of $17.5 \mathrm{~kg} / \mathrm{m}^{2}$. Physical examination revealed no jaundice or hepatosplenomegaly. He showed no muscular weakness of the extremities, but was unable to maintain his limb position when instructed. Flapping tremor was observed in both hands. His consciousness had improved by the following morning, but he was unable to recall how he had got to the hospital. Neurological examination revealed no abnormalities at that time.

Laboratory data revealed mild liver dysfunction (Table). The patient was negative for hepatitis $\mathrm{B}$ surface antigen and anti-hepatitis $\mathrm{C}$ virus antibody. Fasting plasma ammonia levels on admission and the following morning were normal, but the postprandial level was elevated to $154 \mu \mathrm{g} / \mathrm{dL}$, with no obvious neuropsychiatric symptoms. Plasma and urine amino acid analyses showed elevated citrulline levels of $131.4 \mathrm{nmol} / \mathrm{mL}$ and $31.9 \mu \mathrm{mol} / \mathrm{L}$, respectively. Serum pancreatic secretory trypsin inhibitor (PSTI) was elevated to $243.1 \mathrm{ng} / \mathrm{mL}$ and serum ferritin was elevated to about three times the upper limit of normal. Cerebrospinal fluid examination revealed neither elevated protein concentration nor pleocytosis. An electroencephalogram performed 2 days af- ter admission showed background activity composed of 8-9 $\mathrm{Hz}$ alpha waves, with no triphasic waves or epileptic discharges. Brain magnetic resonance imaging (MRI) revealed no obvious abnormalities except for non-specific periventricular white-matter lesions detected on T2-weighted and fluid-attenuated inversion recovery images.

Abdominal ultrasonography (US) showed a bright liver pattern with evident ultrasonographic contrast between hepatic and renal parenchyma. MRI of the liver demonstrated inhomogenous low-intensity lesions on T1-weighted images (Fig. 1A), and the signal intensity of the liver was clearly decreased compared to that of the spleen on T2-weighted images (Fig. 1B). These MRI findings represented hepatic iron deposition. A US-guided liver biopsy specimen revealed hepatocytes containing macrovesicular fat droplets (Fig. 2A, 2B). Moderate hemosiderin deposits were detected, especially in periportal hepatocytes (Fig. 2C). A mild degree of inflammatory reaction and pericellular fibrosis was also observed.

Genomic DNA was extracted from peripheral blood of the patient and his mother after obtaining written informed consent. The sequences of all 18 exons and exon-intron boundaries of the $S L C 25 A 13$ gene were determined according to the method of Dimmock et al. (5), with a minor modification. Two mutations were identified in the patient. One was 

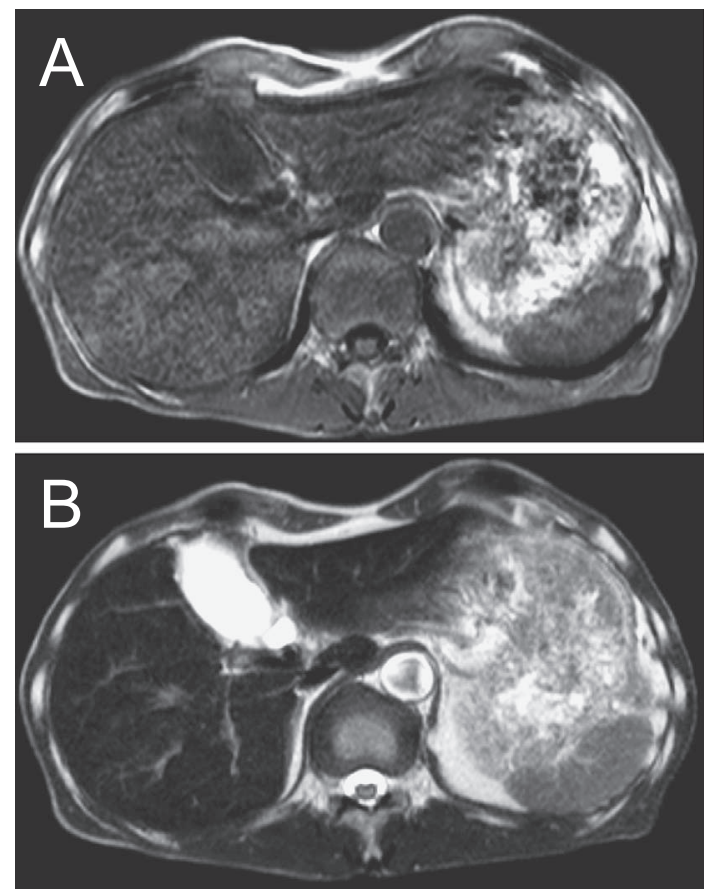

Figure 1. T1-weighted (A) and T2-weighted (B) magnetic resonance images showing a marked low signal intensity of the liver.

a novel c.1478A > $\mathrm{G}$ mutation in exon 15 , resulting in an aspartic acid-to-glycine substitution at position 493 (p.D493 G) (Fig. 3). This mutation was not detected in 100 Japanese control subjects. The other mutation was the known c.674C $>$ A mutation (p.S225X), which was inherited from his mother, indicating that the patient was compound heterozygous for the above two mutations. Mutational analysis of the HFE gene was performed as previously described (6). The patient had neither the p.C282Y nor the p.H63D mutation in the $H F E$ gene.

The patient was diagnosed with CTLN2 and treated with a carbohydrate-restricted, high-fat diet (total calories $=1,900$ $\mathrm{kcal} /$ day; protein: fat: carbohydrate [PFC] ratio=15: 40: 45).

\section{Discussion}

Mutations in the SLC25A13 gene, including nonsense mutations, missense mutations, frameshifts, and splice-site mutations, have been identified in patients with CTLN2. The present patient was compound heterozygous for the previously reported p.S225X (7) mutation and a novel p.D493G mutation. The former has been reported to be a pathological variant in CTLN2 patients and one of the most common mutations detected in Japanese control subjects (1). Asp-493 is located in the fourth transmembrane domain of citrin and is an evolutionarily conserved amino acid residue from Homo sapiens to the cichlid, Oreochromis niloticus, supporting its functional importance. The aspartic acid-to-glycine substitution at position 493 is predicted to be "not tolerated" by the Sorting Intolerant From Tolerant (SIFT) algorithm (8), suggesting that the nonsynonymous mutation
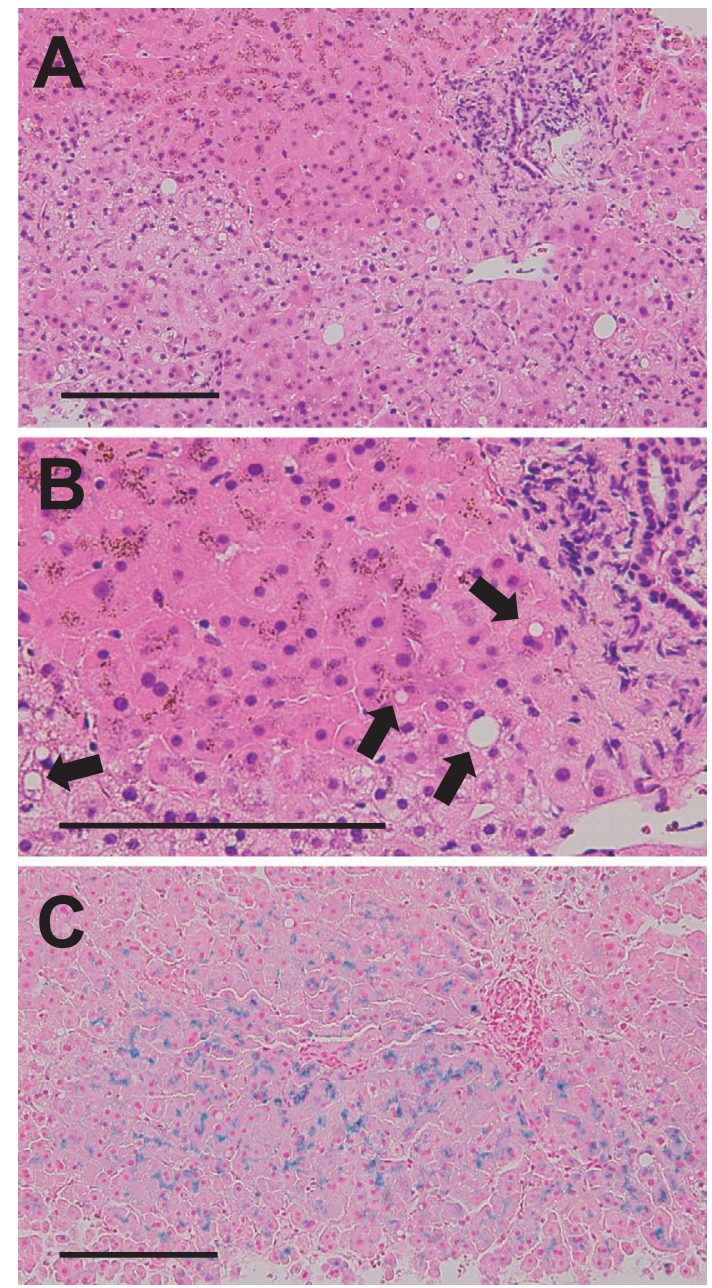

Figure 2. Hematoxylin and Eosin staining (A, B) and Berlin blue stain (C) of liver biopsy specimen. Hepatocytes containing macrovesicular fat droplets (arrows) are detected. Hemosiderin deposits within hepatocytes are observed mainly in the periportal area. Inflammatory cell infiltration is also observed. Scale bars $=200 \mu \mathrm{m}$.

leads to functional impairment.

In the present patient, the initial symptom was observed at the age of 62 years. Yasuda et al. reported that six out of 102 genetically confirmed CTLN2 patients experienced disease onset after the age of 60 years (9). Mutations in the SLC25A13 gene are responsible for CTLN2, but there is no correlation between genotype and phenotype. In addition, considering the carrier rate in control subjects, the incidence of CTLN2 is lower than the calculated frequency of homozygotes with SLC25A13 gene mutations. In other words, individuals with SLC25A13 gene mutation(s) in both alleles may remain apparently healthy throughout their entire lives. These observations imply that additional genes or environmental factors, such as characteristic food preferences, may modify the pathological mechanism(s) responsible for citrin deficiency. Most patients with CTLN2 are known to have an aversion to carbohydrate-rich foods. However, the present patient had started to eat carbohydrate-rich meals such as noodles 3 months before disease onset, and the estimated 


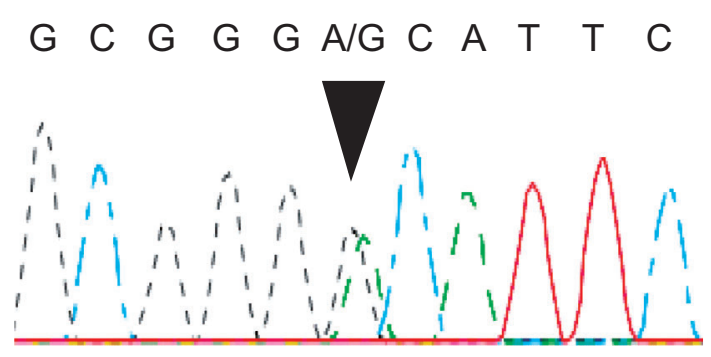

Figure 3. Electrophoretogram of the patient's DNA sequence showing a heterozygous A-to-G transition (arrowhead) in exon 15 of the $S L C 25 A 13$ gene (c.1478A>G), resulting in an aspartic acid-to-glycine substitution at position 493 (p. D493G).

PFC ratio was 12: 13: 70. This change in diet could have triggered the onset of the disease in the present case.

Most patients with CTLN2 have fatty changes of the liver unrelated to obesity and metabolic syndrome. Komatsu et al. reported that low body mass index was characteristic of CTLN2-related fatty liver changes (10). In addition, elevated serum PSTI level was also associated with this condition, whereas patients with non-alcoholic fatty liver disease (NAFLD) unrelated to SLC25A13 gene mutations showed no elevation of PSTI. Histologically, fat deposition in hepatocytes is observed in CTLN2, together with varying degrees of fibrosis, inflammatory cell infiltration, and cholestasis. Interestingly, the present case showed a marked elevation of serum ferritin, with hemosiderin deposition in the liver. Kimura et al. reported hemosiderin deposition in liver biopsy specimens in $57 \%$ of patients with geneticallyconfirmed NICCD (11). They also demonstrated elevated serum ferritin levels in all tested patients. Serum ferritin levels are known to be elevated in patients with NAFLD, nonalcoholic steatohepatitis, and chronic hepatitis $\mathrm{C}$, as well as in the general population in relation to alcohol consumption. Pro-inflammatory cytokines and oxidative stress have been reported to be associated with increased serum ferritin levels in these conditions $(12,13)$. Tung et al. reported that mutations in the HFE gene (encoding the human hemochromatosis protein) led to hepatic iron overload, hyperferritinemia, and accelerated hepatic fibrosis in patients with chronic hepatitis C (14), although neither the p.C282Y nor the p.H 63D mutation in the $H F E$ gene was detected in the present case. Although the exact mechanism by which SLC25A13 gene mutations lead to abnormal iron metabolism or CTLN 2-related fatty liver changes remains unclear, hyperferritinemia might represent a characteristic finding of this disease.

In conclusion, we identified a novel p.D493G mutation in the SLC25A13 gene in a patient with CTLN2. CTLN2 should be considered, even in elderly patients, in the event of new-onset neuropsychiatric manifestations. In addition to postprandial plasma ammonia profiles, elevated serum ferritin might be one of the characteristic findings of CTLN2.

The authors state that they have no Conflict of Interest (COI).

\section{References}

1. Saheki T, Kobayashi K. Mitochondrial aspartate glutamate carrier (citrin) deficiency as the cause of adult-onset type II citrullinemia (CTLN2) and idiopathic neonatal hepatitis. J Hum Genet 47: 333341, 2002.

2. Kobayashi K, Sinasac DS, Iijima M, et al. The gene mutated in adult-onset type II citrullinemia encodes a putative mitochondrial carrier protein. Nat Genet 22: 159-163, 1999.

3. Ikeda S, Yazaki M, Takei Y, et al. Type II (adult onset) citrullinaemia: clinical pictures and the therapeutic effect of liver transplantation. J Neurol Neurosurg Psychiatry 71: 663-670, 2001.

4. Saheki T, Kobayashi K, Iijima M, et al. Metabolic derangements in deficiency of citrin, a liver-type mitochondrial aspartateglutamate carrier. Hepatol Res 33: 181-184, 2005.

5. Dimmock D, Maranda B, Dionisi-Vici C, et al. Citrin deficiency, a perplexing global disorder. Mol Genet Metab 96: 44-49, 2009.

6. Uto H, Kurogi J, Takahama Y, et al. Alanine aminotransferase flare-up in hepatitis $\mathrm{C}$ virus carriers with persistently normal alanine aminotransferase levels in a hyperendemic area of Japan. J Gastroenterol 42: 673-680, 2007.

7. Tabata A, Sheng JS, Ushikai M, et al. Identification of 13 novel mutations including a retrotransposal insertion in SLC25A13 gene and frequency of 30 mutations found in patients with citrin deficiency. J Hum Genet 53: 534-545, 2008.

8. Kumar P, Henikoff S, Ng PC. Predicting the effects of coding non-synonymous variants on protein function using the SIFT algorithm. Nat Protoc 4: 1073-1081, 2009.

9. Yasuda T, Yamaguchi N, Kobayashi K, et al. Identification of two novel mutations in the SLC25A13 gene and detection of seven mutations in 102 patients with adult-onset type 11 citrullinemia. Hum Genet 107: 537-545, 2000.

10. Komatsu M, Yazaki M, Tanaka N, et al. Citrin deficiency as a cause of chronic liver disorder mimicking non-alcoholic fatty liver disease. J Hepatol 49: 810-820, 2008.

11. Kimura A, Kage M, Nagata I, et al. Histological findings in the livers of patients with neonatal intrahepatic cholestasis caused by citrin deficiency. Hepatol Res 40: 295-303, 2010.

12. Manousou P, Kalambokis G, Grillo F, et al. Serum ferritin is a discriminant marker for both fibrosis and inflammation in histologically proven non-alcoholic fatty liver disease patients. Liver Int 31: 730-739, 2011.

13. Neuschwander-Tetri BA, Clark JM, Bass NM, et al. NASH Clinical Research Network. Clinical, laboratory and histological associations in adults with nonalcoholic fatty liver disease. Hepatology 52: 913-924, 2010.

14. Tung BY, Emond MJ, Bronner MP, Raaka SD, Cotler SJ, Kowdley KV. Hepatitis C, iron status, and disease severity: relationship with HFE mutations. Gastroenterology 124: 318-326, 2003.

(C) 2012 The Japanese Society of Internal Medicine http://www.naika.or.jp/imonline/index.html 